\title{
El diálogo judicial euro-latinoamericano en el tema de leyes de amnistía: un ejemplo de cross-fertilization entre tribunales de Derechos Humanos ${ }^{1}$
}

\section{The Euro-Latin American Judicial Dialogue on the Issue of Amnesty Laws: an Example of Cross-Fertilization between Human Rights Courts}

\author{
Miguel Arenas Meza \\ Universidad de Santiago de Compostela (España)
}

Recibido: 03-07-18

Aprobado: 18-08-18

\section{Resumen}

El proceso de cross-fertilization entre tribunales de derechos humanos se ha convertido en una pieza fundamental en torno a la cual se sustenta la unidad del sistema universal de protección. Dicho proceso se ha hecho especialmente evidente en las relaciones entre el TEDH y la Corte IDH, en dónde en los últimos tiempos se observa una creciente interacción e influencia recíproca entre ambos tribunales en diversos ámbitos temáticos, entre los que destaca en particular el relacionado con las leyes de amnistía. En este sentido, el objeto del trabajo es analizar el proceso de cross-fertilization jurisprudencial entre estos dos tribunales en relación con dicha temática, mostrando cómo en este caso concreto ha sido la

\footnotetext{
${ }^{1}$ Este trabajo se ha desarrollado en el marco de las "Axudas do Programa de Consolidación e Estruturación de Unidades de Investigación Competitivas-Ano 2017. Modalidade: Grupos con Potencial de Crecimiento", financiado de la Conselleria de Cultura, Educación y Ordenación Universitaria de la Xunta de Galicia, que ha permitido a su autor realizar una estancia de investigación en el "Max Planck Institute for Comparative Public Law and International Law" (Heidelberg, Alemania).

${ }^{2}$ (miguelenrique.arenas@usc.es). Profesor Contratado Doctor en la Universidad de Santiago de Compostela. Licenciado en Derecho por la Pontificia Universidad Católica del Perú (Lima) y Doctor en Derecho por la Universidad de Santiago de Compostela. Ha realizado diversas estancias de investigación tanto en centros extranjeros como en españoles. Es autor de diversas monografías y artículos en publicaciones extranjeras y nacionales sobre temas relacionados con el uso de la fuerza, las disputas territoriales y cuestiones de defensa, el Derecho internacional de las pesquerías, los Derechos Humanos y el arreglo de las controversias, el Derecho de las inversiones, los pueblos indígenas entre otros muchos.
} 
jurisprudencia interamericana la que ha ejercido una influencia notable sobre la actual configuración del case law europeo en esta materia.

Palabras-clave: Leyes de amnistía; diálogo judicial; Tribunal Europeo de Derechos Humanos; Corte Interamericana de Derechos Humanos; fertilización cruzada; graves violaciones de derechos humanos.

\section{Abstract}

The process of "cross-fertilization" among human rights courts has become a fundamental element around which the unity of the universal system of protection of human rights is based. This process has become especially evident in the relations between the ECtHR and the ICHR, considering that in recent times there has been increasing interaction and reciprocal influence between these two courts in various thematic areas. Among these areas, the one related to amnesty laws stands out. In this sense, the purpose of the paper is to analyze the cross-fertilization jurisprudential process between these two human rights courts in relation to this topic, showing how in this case it has been interAmerican jurisprudence that has exerted a remarkable influence on the current configuration of the European case law in this matter.

Key-words: Amnesty laws; judicial dialogue; European Court of Human Rights; Inter-American Court of Human Rights; cross-fertilization; gross human rights violations.

\section{Introducción}

La creciente coordinación y diálogo que se viene produciendo entre tribunales internacionales y regionales de protección de derechos humanos constituye uno de los rasgos más característicos en torno a los cuales se sustenta el actual régimen universal de protección. Existe en este sentido un amplio consenso en cuanto a que el creciente proceso de cross-fertilization jurisprudencial que se viene dando entre tribunales, en virtud del cual los órganos de derechos humanos se refieren y se ven influenciados por las decisiones de otros tribunales, está contribuyendo decisivamente a la armonización jurisprudencial en esta materia así como también a la interpretación uniforme de los estándares internacionales en este ámbito; lo cual, ciertamente, favorece a la universalidad Derecho Internacional de los Derechos Humanos (en adelante DIDH).

Quizá el ejemplo más destacado de este proceso de cross-fertilization lo encontremos en el diálogo judicial que mantienen el Tribunal Europeo de Derechos Humanos (en adelante TEDH) y la Corte Interamericana de 
Derechos Humanos (en adelante Corte IDH) desde hace algún tiempo. Existen, en efecto, diversos ámbitos temáticos en los se ha puesto de manifiesto este cross-referencing jurisprudencial entre estos dos tribunales, siendo uno de ellos el relacionado con las leyes de amnistía, en el que, a diferencia de lo ocurrido con otros ámbitos materiales, ha sido el TEDH el que se ha servido de la jurisprudencia interamericana y sobre todo, de los casos más emblemáticos o leading cases del case law americano en la materia, para emitir su decisión en un determinado asunto.

En estas decisiones del TEDH existen puntos más que notables de convergencia con los de su contraparte americana y todo ello como una muestra evidente de que existe un diálogo judicial fluido entre estos dos tribunales y de que ambos comparten la misma idea en cuanto a que, en ciertos casos, las leyes de amnistía resultan incompatibles con las disposiciones de las Convenciones americanas y europea de protección de derechos humanos.

Partiendo de estas consideraciones generales, el objeto del trabajo es analizar cómo, en el marco del diálogo judicial euro-latinoamericano, se ha llevado a cabo este proceso de cross-fertilization jurisprudencial entre el TEDH y la Corte IDH en el tema de leyes de amnistía. A tal objeto el trabajo se estructura en tres partes. En una primera, se aborda con carácter general el tema del diálogo judicial entre tribunales de derechos humanos y como éste constituye una pieza clave para la unidad de dicho sistema de protección. Tras ello, en una segunda parte, se examinan los aspectos generales del diálogo judicial entre el TEDH y la Corte IDH, particularmente los términos en qué se viene produciendo dicho diálogo así como el contenido temático del mismo. En la última parte del trabajo se analiza el diálogo judicial entre ambos tribunales en el contexto específico de las leyes de amnistía. En este punto, se hace ver cómo en un primer momento ése diálogo entre tribunales fue prácticamente inexistente, a pesar de la innegable autoridad que ha tenido el case law interamericano en esta materia desde tiempo atrás. Sin embargo, veremos cómo en épocas más recientes se ha producido un cambio significativo en la jurisprudencia del Tribunal de Estrasburgo como consecuencia directa de la influencia ejercida por la jurisprudencia americana sobre la misma.

\section{El diálogo judicial entre tribunales internacionales: un elemento esencial para la unidad de los derechos humanos}

La proliferación de tribunales internacionales constituye uno de los rasgos más característicos del actual Derecho internacional. Si bien cada uno de estos tribunales goza de autonomía funcional y orgánica, existen evidentes muestras acerca de un paulatino proceso de comunicación entre los mismos. Y de que no 
se trata simplemente de tomar prestado (judicial borrowing) o de "importar" la jurisprudencia externa, como ha sido hasta ahora lo habitual, sino de la búsqueda de formas más articuladas de interacción jurisprudencial de tipo "dialógico", que pueda conducir, en algunos casos, a una verdadera fertilización cruzada (cross-fertilization) entre tribunales ${ }^{3}$. Es decir, un fenómeno en virtud del cual los tribunales internacionales se inspiran y tienen en cuenta las experiencias de otros tribunales, incluso haciendo mención a los precedentes de dichos tribunales en sus sentencias; estableciendo, de este modo, un diálogo judicial entre ellos ${ }^{4}$.

Este diálogo se ha dado particularmente entre tribunales internacionales y regionales en el ámbito del Derecho Internacional de los Derechos Humanos (en adelante DIDH). Su creciente expansión en épocas recientes ha supuesto una invalorable contribución a la evolución armoniosa de la jurisprudencia de derechos humanos, así como también a la interpretación uniforme de sus estándares, reglas y principios. En ésa medida, se trata de un diálogo que favorece la unidad y la cohesión de dicho sector normativo, descartando así los riesgos derivados de su posible fragmentación. Por todo ello, es posible afirmar que este continuo proceso de cross-fertilization e interacción entre tribunales internacionales constituye una de las piezas fundamentales en torno a las cuales se articula el universalismo del régimen de tutela de los derechos humanos ${ }^{5}$.

\section{El diálogo judicial entre el tribunal europeo de derechos humanos y la corte interamericana de derechos humanos: aspectos generales}

\section{A. La relación del TEDH con "fuentes externas" al sistema europeo de protección}

Pese a que en su labor de interpretación de las disposiciones del CEDH y de sus Protocolos el TEDH se ha guiado básicamente por su propio case law, en ocasiones pueden surgir casos en los que deba recurrir a "fuentes externas" para llevar a cabo dicha tarea. Cuando ello ha sido necesario, el Tribunal se

\footnotetext{
${ }^{3}$ Véase Angela Di Stasi, "La Corte interamericana e la Corte Europea dei diritti dell'uomo: da un transnational judicial dialogue ad una cross -fertilization?" [en Luisa Cassetti,, Angela Di Stasi y César Landa Arroyo, coords.: Diritti e giurisprudenza. La Corte interamericana dei diritti umani e la Corte europea di Strasburgo, Napoli, Jovene Editore, ,2014], p. 1.

4 Chloe Cheeseman, "Harmonising the Jurisprudence of Regional and International Human Rights Bodies. A Literature Review" [en Carla Buckley, Alice Donald,. Philip Leach, eds.: Towards Convergence in International Human Rights Law. Approaches of Regional and International Systems, Leiden, Brill Nijhoff, 2017], p. 596.

${ }^{5}$ Antonio Augusto Cançado Trindade, "Preface: International Tribunals and the Pursuance o Jurisprudential Harmonization in their Common Misssion of Realisation of Justice"[ en Carla Buckley, Alice Donald,. Philip Leach, eds.: Towards Convergence in International Human Rights Law. Approaches of Regional and International Systems, Leiden, Brill Nijhoff, 2017], p. I-XX.
} 
ha referido a otros instrumentos internacionales y regionales de protección de derechos humanos, así como también a la jurisprudencia y decisiones de los tribunales y órganos que supervisan su correcta aplicación por las partes contratantes, en orden a apoyar su decisión en un asunto determinado ${ }^{6}$.

La utilización de estas fuentes externas se ha hecho especialmente visible inter alia cuando el Tribunal ha buscado obtener información acerca de cómo otros sistemas internacionales de protección de derechos humanos han resuelto cuestiones y problemas similares a los que se le plantean en algún asunto que está examinando y que el CEDH no aborda de manera específica ${ }^{7}$. Pues bien, es justamente en este tipo de situaciones cuando el Tribunal de Estrasburgo se ha visto precisado a dialogar y coordinarse con otros sistemas regionales de protección. Y ello en la medida en que los tribunales y órganos de regionales le pueden suministrar una valiosa información acerca de cómo los derechos humanos son entendidos y desarrollados en otras partes del mundo. Por lo que la mención a casos decididos en otros ámbitos regionales le puede ser de una inestimable ayuda al Tribunal al momento de interpretar las disposiciones del Convenio europeo.

\section{B. Los términos del diálogo judicial entre el TEDH y la Corte IDH}

En sus relaciones con los distintos sistemas regionales de protección existentes, hay que destacar la especial relación que mantiene el Tribunal de Estrasburgo con el sistema interamericano de protección y, de manera particular, con la Corte $\mathrm{IDH}^{8}$. Una comunicación que se ha visto facilitada en gran medida

\footnotetext{
${ }^{6}$ En torno a la "importación" de fuentes externas por parte del TEDH, véase entre otros: Magdalena Forowicz, The Reception of International Law in the European Court of Human Rights, Oxford, Oxford University Press, 2010, pp.382-385; Ibid., "Factors influencing the reception of International Law in the ECtHR's case law: an overview", [en Mads Andenas, M. y Eirik Bjorge, eds., A Farewell to Fragmentation. Reassertion and Convergence in International Law, Cambridge, Cambridge University Press, 2015], pp. 191-217; Lech Garlicki, "Universalism v. Regionalism? The Role of the Supranational Judicial Dialogue”, [en Javier García Roca, Pablo Antonio Fernández Sánchez, Pablo Santolaya Machetti, y Raul Canosa Usera, eds.: El Diálogo entre los Sistemas Europeo y Americano de Derechos Humanos, Thomson Reuters, Pamplona, 2012], p. 54; Dorothea Staes, "The importation of "External Sources" by the European Court of Human Rights. Opportunities and Challenges in Light of Legal Certainty", [en Mauricio Arcari, y Louis Balmond, eds.: Le dialogue des jurisdictions dans l'ordre juridique internationale. Entre pluralisme et securité juridique, Napoli, Ed. Scientifica, 2014], pp. 61-88; Erik Voeten, "Borrowing and Non-Borrowing among International Courts" en Journal of Legal Studies, 2 (2010), pp. 547-576.

${ }^{7}$ De modo significativo esto ha ocurrido cada vez que el Tribunal y la Comisión han querido aclarar o ampliar el significado de la Convención y no eran capaces de encontrar orientaciones en su propia jurisprudencia (Forowicz, "The Reception...", op. cit,, p. 383). En estos casos, los órganos europeos de protección han entendido que esas fuentes externas le pueden proporcionar "occasional guidance"(ibid.).

${ }^{8}$ Sobre las relaciones entre el TEDH y la Corte IDH véase Javier García Roca, "El Diálogo sobre Derechos Humanos entre el Tribunal Europeo y la Corte Interamericana" [ en Pablo Santolaya Marchetti e Isabel Wences, coords.: La América de los Derechos, Madrid, Centro de Estudios Constitucionales , 2016], pp. 533-564; Tania Groppi, y Ana María Lecis Cocco-Ortu, "Las referencias recíprocas 
por el hecho de que ambos sistemas de protección comparten unos elementos comunes. No sólo en lo que se refiere al contenido sustancial de los derechos humanos que protegen, sino también por el marcado parecido que existe en los instrumentos de garantía procesal previstos en sus respectivos Convenios para garantizar la efectiva aplicación de los referidos derechos ${ }^{9}$.

Es por ello que el sistema interamericano se ha convertido en una de las fuentes naturales de inspiración e información del sistema de Estrasburgo, probablemente la más importante. De ahí que cuando el Tribunal tiene ante sí algún asunto cuya complejidad haga necesario considerar lo establecido en otros sistemas regionales de protección, las referencias a la $\mathrm{CADH}$ y a las decisiones de la Corte IDH y de la CIDH, constituirán una parte importante de la decisión que vaya adoptar el Tribunal en ése caso ${ }^{10}$.

Esto no significa, sin embargo, que el papel que le asigna el Tribunal a estas referencias del sistema interamericano sea siempre el mismo. Existen al menos tres situaciones en las que la información del sistema interamericano puede ser incluida en las decisiones del Tribunal. En primer lugar, dicha información puede ser introducida como una simple referencia sin mayor relevancia para la resolución del caso. Ello ocurre cuando el Tribunal desea mostrar su amplio conocimiento de la jurisprudencia interamericana y decide incluir algún asunto del case law americano en el apartado de la sentencia dedicado al "Derecho internacional", pero luego no lo alude expresamente en el fundamento de su ratio decidendi ${ }^{l l}$. La segunda situación se produce

entre el Tribunal Europeo y la Corte Interamericana de Derechos Humanos: ¿De la influencia al diálogo?, en Revista de Derecho Político (UNED), 91 (2014), pp. 183-230; Gerald Neuman, "Import, Export and Regional Consent in the Inter-American Court of Human Rights, en European Journal of International Law, 1 (2008), pp. 101-123; Ibid.., "The External Reception of Inter-American Human Rights Law, en Quebec Journal of International Law (Special Edition), (2011), pp. 99-125; Flávia Piovesan, "Diálogo entre Cortes: A interamericanizaçao do sistema europeo e a europeizaçao do sistema interamericano"[ en Flávia Piovesan y Jania María Lopes Saldanha, coords.: Diálogos Jurisdicionais e Direitos Humanos, Brasilia, Gazeta Jurídica Editora e Livraria Ltda. ME, 2016], pp. 175-196.

${ }^{9}$ Garlicki, op. cit, p. 31. Además este diálogo se ha visto favorecido por el hecho de que ambos sistemas regionales de protección derivan de un mismo tronco común, esto es el sistema universal de garantía de derechos humanos $\mathrm{y}$, en ésa medida, poseen un parámetro de enjuiciamiento que es en parte común; compuesto por una serie de instrumentos universales como la Declaración Universal de Derechos Humanos, el Pacto sobre Derechos Civiles y Políticos -tal y como ha sido interpretado y aplicado por el Comité de Derechos Humanos-, el Pacto Internacional de Derechos Económicos, Sociales y Culturales, las convenciones especializadas de Naciones Unidas, así como también las convenciones elaboradas en el marco de la Organización Internacional del Trabajo (OIT) y otras organizaciones similares (García Roca, op. cit,, pp. 537). Todos este cúmulo de elementos comunes, como ha sido mencionado, "costituiscono un humus fecondo rispetto di trans-regional judicial dialogue se non di vera e propia cross-fertilization..." entre ambos órganos jurisdiccionales de derechos humanos". (Di Stasi, op. cit, p. 16)

${ }^{10}$ De hecho, en todos los casos importantes que tiene ante sí, el Tribunal europeo invariablemente investiga la "amplia experiencia y el impresionante record de la Corte IDH" en la protección de los derechos humanos (Garlicki, op. cit., p. 64).

${ }^{11}$ En este caso específico se ha hablado de la existencia de una suerte de diálogo "encubierto" o hidden dialogue entre ambos tribunales de derechos humanos (García Roca, op. cit., p. 542). 
cuando el Tribunal, teniendo pleno conocimiento de la solución adoptada en el sistema interamericano, no se muestra dispuesto o no está preparado para adoptar un enfoque similar y así lo hace notar expresamente en la sentencia, precisando que su enfoque es distinto al de su contraparte interamericana ${ }^{12}$. Y por último, aunque no por ello menos importante, el Tribunal se ha referido a la jurisprudencia interamericana como un argumento para legitimar una nueva interpretación de un determinado tema y el consiguiente cambio de orientación en su jurisprudencia. En este caso, las referencias al case law interamericano tienen un propósito claramente legitimador en la medida en que ayudan al Tribunal a convencer a los Estados partes en el Convenio de que su nuevo enfoque jurisprudencial se encuentra plenamente justificado ${ }^{13}$. Es decir, que el Tribunal se apoya en la autoridad de dicha jurisprudencia para justificar el cambio de su propio case law.

Es en el marco de esta función legitimadora en el que las referencias a la jurisprudencia de la Corte IDH se convierten en realmente importantes, ya que la indicación de que un problema ha sido abordado y resuelto de una manera similar en otro sistema internacional de protección de los derechos humanos -como el interamericano-, le sirve de gran ayuda al Tribunal a la hora de justificar sus argumentos. Y es precisamente en este contexto "legitimador" cuando el proceso de cross-fertilization entre ambas jurisdicciones de derechos humanos se ha materializado.

\section{El contenido del diálogo judicial entre ambos tribunales: ámbitos temáticos}

En los primeros años de existencia del Tribunal las referencias a la jurisprudencia de la Corte IDH fueron casi inexistentes. Las únicas menciones a dicho case law fueron hechas directamente por los denunciantes, o bien por terceros intervinientes al exponer el caso, y ello con el objetivo de animar al TEDH a que modifique la interpretación de los asuntos de

${ }^{12}$ El hecho de que existan divergencias o disidencias en torno a una determinada cuestión no significa automáticamente la ausencia de diálogo o de influencia recíproca entre tribunales (Neuman "The External reception...", op. cit, p. 101). Pudiera tratarse simplemente de un problema de grado de desacuerdo en las opiniones, ya que lo realmente importante es impedir las contradicciones entre los sistemas de protección y alejar una perspectiva aislacionista que permita desentenderse del otro sistema (Garcia Roca, op. cit, , pp. 536-537).

13 En este supuesto la mención que hace el TEDH del case law interamericano tiene por objeto aumentar la legitimidad de su propia decisión y reforzar su argumentación jurídica (Garcia Roca, op. cit, p. 542; Staes, op. cit. p. 72-73). O lo que es lo mismo, dichas referencias le sirven al Tribunal europeo como una fuente dotada de una gran eficacia persuasiva para demostrar "support for his stated understanding of the law" (Cheeseman, op. cit, pp. 614-615; Neuman "The External reception...", op. cit, p. 127),). Esta utilización del case law interamericano no podría darse si no existiese la convicción de que existe una base común (common ground) entre el ordenamiento en el cual se ha adoptado la decisión y el ordenamiento en el cual se cita (Groppi y Lecis Cocco-Ortu, op. cit, p. 218). 
derechos humanos conforme a lo realizado por la Corte interamericana ${ }^{14}$. En distintas ocasiones, al presentar las posiciones de las partes, el Tribunal hizo notar esas referencias hechas al case law interamericano. Pero en todo momento se mostró poco dispuesto a mencionarlas explícitamente en los fundamentos de su decisión final ${ }^{15}$.

Esta situación va a empezar cambiar a partir de la primera década del presente siglo, cuando el Tribunal va a comenzar a referirse esporádicamente a las decisiones de los órganos de supervisión y protección en el sistema interamericano y a tomarlas en cuenta en los fundamentos de su decisión final ${ }^{16}$. No obstante se ha criticado el hecho que el Tribunal europeo se haya referido a la referida jurisprudencia "in a limited and selective fashion"17.

Si bien exceden los objetivos de este trabajo examinar toda esa extensa práctica $^{18}$, sí que nos gustaría hacer una breve mención a los ámbitos temáticos en los cuales se han producido las citas de casos del sistema interamericano por

14 Estas tentativas por establecer un diálogo entre el Tribunal europeo y la jurisprudencia interamericana, al margen de los órganos jurisdiccionales implicados, y que fueran promovidas tanto por los justiciables en provecho de sus tesis como por terceros intervinientes -amicus curie-, ONG's o incluso grupos de académicos, han sido calificadas desde la doctrina como un intento de establecer un diálogo indirecto entre tribunales (Véase la respecto, Garlicki, op. cit, p. 58).

${ }^{15}$ Cosa distinta a lo sucedido con la Corte IDH, la cual siempre se ha mostrado dispuesta a tomar como referencia las posiciones asumidas por el TEDH y a mencionarlas directamente en su jurisprudencia para darle un mayor apoyo a su interpretación de las disposiciones de la Convención americana (Di Stasi, op. cit, pp. 16-17; Neuman “Import...”, op. cit, p. 109; Voeten, op. cit., p. 563). Esta amplia utilización del case law europeo por la Corte IDH en comparación con la escasa referencia por el TEDH de la jurisprudencia americana ha llevado a algunos autores a describir el diálogo entre ambos tribunales, como un "diálogo unidireccional" o incluso como un "monólogo judicial" por parte del tribunal europeo. (Véase Cheeseman, op. cit. pp. 599-600 y 602; García Roca, op. cit, pp. 545546). Si bien esta descripción sigue manteniéndose en gran medida, hay elementos de la práctica que nos permiten avizorar un cambio.

${ }_{16}$ Probablemente los dos casos más representativos de este cambio jurisprudencial sean el Caso Varnava y otros $v$. Turquía (TEDH. № 16064/90, Sentencia de 18 de septiembre de 2009, párrs.. 97- 98), en el tema de desapariciones forzadas y el Caso Mamatkulov y Askarov v. Turquía (TEDH. $\mathrm{N}^{\circ} 46827 / 99,46951 / 99$, Sentencia de 4 de febrero de 2005, párrs.. 123 -124), en el tema de medidas provisionales, pues en ambos las referencias al case law americano tuvo una importancia decisiva en las conclusiones finales del Tribunal. Si bien estas primeras referencias al case law americano son más bien exiguas desde un punto de vista cuantitativo, "no parecen irrelevantes desde un punto de vista cualitativo" (Groppi y Lecis Cocco-Ortu, op. cit, p. 192).

17 Staes, op. cit, p. 78.

18 Véase al respecto el reciente Informe del TEDH en dónde se enumeran una importante cantidad de casos de dicho tribunal con referencias expresas a decisiones de los órganos de supervisión y protección del sistema interamericano de protección de derechos humanos. ECHR, Research Report. References to the Inter-American Court of Human Rights and Inter-American instruments in the case-law of the European Court of Human Rights, 2016. El texto en cuestión está actualizado a 1 de noviembre de 2016 (disponible en: www.ecchr.coe.int (Case- law- Case- Law Analysis- Research Reports). Como puede apreciarse, las referencias al sistema interamericano por parte del TEDH no sólo incluye menciones a la propia CADH y sus Protocolos adicionales, sino también a decisiones de la $\mathrm{CIDH}$, a la jurisprudencia de la Corte IDH, e incluso a Opiniones Consultivas de esta última. Todas estas menciones se encuentran recogidas en la propia sentencia así como en los Votos particulares o concurrentes de los jueces. (ver Di Stasi, op. cit., p. 23).

Araucaria. Revista Iberoamericana de Filosofía, Política, Humanidades y Relaciones Internacionales, año 20, $\mathrm{n}^{\circ} 40$. Segundo semestre de 2018. Pp. 577-604. ISSN 1575-6823 e-ISSN 2340-2199 doi: 10.12795/araucaria.2018.i40.24 
el TEDH, en la medida en que ello permitirá darnos una idea de la dimensión que ha adquirido el diálogo judicial entre estos dos tribunales, y de que éste se proyecta a una diversidad de ámbitos materiales.

Tomando como referencia el mencionado Informe de 2016 se desprende que dicho diálogo se ha centrado fundamentalmente en ámbitos como el de desapariciones forzadas; las medidas provisionales; la pena de muerte: su carácter irreversible y la necesidad de un debido proceso; la inversión y distribución de la carga de la prueba en el agotamiento de los recursos internos razonablemente exigibles; la revelación de información confidencial: la transparencia y control del Gobierno; la interpretación de que el principio non bis idem viene ligada a unos mismos hechos; las obligaciones autónomas de procedimiento derivadas del derecho a la vida y jurisdicción ratione tempori; la obligación de investigar las violaciones del derecho a la vida continúan aplicándose en situaciones de conflictos armados o violencia generalizada; el principio de legalidad penal: aplicación retroactiva de la pena más leve implantada incluso tras la comisión del delito; las amenazas de tortura pueden sumarse a las torturas; la exclusión de civiles de la jurisdicción militar; la vulnerabilidad de las víctimas de violencia doméstica; la violencia contra las mujeres y prohibición de cualquier forma de discriminación, y también en el tema de leyes de amnistía, sobre el cual volveremos más adelante ${ }^{19}$.

En todos estos ámbitos temáticos se detecta, con mayor o menor grado, la presencia de unos estándares compartidos entre el TEDH y la Corte IDH en cuestiones de relevancia, lo cual es indicativo de que los jueces europeos siguen de cerca la jurisprudencia interamericana y de que el diálogo entre ambos tribunales es una realidad.

\section{El diálogo judicial entre el tedh y la corte idh en el tema de leyes de amnistía: un ejemplo de cross-fertilization entre tribunales}

Tras haber examinado en el apartado anterior los aspectos generales del diálogo judicial entre el TEDH y la Corte IDH, en el contexto de la influencia que ejerce el case law interamericano sobre la jurisprudencia de del Tribunal de Estrasburgo, en esta última parte del trabajo nos proponemos analizar el desarrollo de dicho diálogo en el ámbito específico del de las leyes de amnistía. Sobre todo teniendo en cuenta que, en dos sentencias relativamente recientes ${ }^{20}$, el Tribunal se refirió directamente a la jurisprudencia interamericana para

19 Esta amplitud temática en las "exportaciones" del case law americano a la jurisprudencia europea, ha llevado a algún autor a sugerir que "la situación podría estar cambiando poco a poco" y que nos estaríamos encaminando hacia un " diálogo bidireccional” entre ambos tribunales (García Roca, op. cit, p. 546).

${ }^{20}$ Vid. , infra, apartado B.

Araucaria. Revista Iberoamericana de Filosofia, Política, Humanidades y Relaciones Internacionales, año 20, $\mathrm{n}^{\circ} 40$. Segundo semestre de 2018. Pp. 577-604. ISSN 1575-6823 e-ISSN 2340-2199 doi: 10.12795/araucaria.2018.i40.24 
justificar el cambio de su anterior case law, reconociendo de este modo la enorme autoridad que tiene dicha jurisprudencia en esta temática ${ }^{21}$.

En tal sentido, empezaremos abordando la posición de los órganos europeos en torno a las leyes de amnistía antes de las mencionadas sentencias, y en dónde se constata que en su valoración de la compatibilidad de dichas leyes con el CEDH, éstos no hicieron mención explícita al case law interamericano, si bien ello no quiere decir que no hayan tenido en cuenta dicha jurisprudencia. A continuación, en una segunda parte, analizamos la posición de los órganos europeos después de las antedichas sentencias, y en dónde se observa nítidamente un cambio en relación con la situación anterior, pues el Tribunal se va a referir directamente al case law interamericano para darle mayor legitimidad y autoridad a sus decisiones. Este cambio en el case law europeo obedece, sin duda alguna, al creciente proceso de cross-fertilization que se viene dando en los últimos tiempos entre estos dos tribunales regionales de protección de derechos humanos.

\section{A. El tema de las leyes de amnistía en las primeras decisiones de los órganos europeos de protección de derechos humanos: ¿inexistencia de diálogo con su contraparte americana?}

En el sistema europeo de protección de derechos humanos, a diferencia de lo que ocurre en otros sistemas regionales de protección, han sido contadas las ocasiones en las que los órganos de protección - tanto la Comisión como el Tribunal- , han entrado a hacer valoraciones en torno a las leyes de amnistía y su posible compatibilidad con las disposiciones del CEDH. En los pocos casos en los que sí lo han hecho, se constata que existe una cierta diferencia entre la evaluación y el juicio realizados por los órganos europeos y la realizada por los demás órganos internacionales de protección, incluidos los interamericanos, especialmente en lo que concierne a los criterios que se exigen para que dichas

\footnotetext{
${ }^{21}$ Sobre la jurisprudencia de la Corte interamericana en el tema de leyes de amnistía véase entre otros, Miguel Arenas Meza "La contribución de la jurisprudencia de la Corte Interamericana de Derechos Humanos a la eliminación de las "leyes de amnistía" [en América Latina: un paso decisivo en la lucha contra la impunidad", Actas del XIV Encuentro de Latinoamericanistas Españoles, Santiago de Compostela, Servicio de Publicacións de la Universidade de Santiago de Compostela, 2010], pp. 2171 2189; Jonas- Sébastien Beaudry, "La invalidez ab initio de las leyes de amnistía en América Latina: la contribución de la Corte Interamericana de Derechos Humanos", en Revista General de Legislación y Jurisprudencia, 1 (2010), pp. 29-64; Laurence Burgorgue-Larsen, "La lutte contre 1'impunité dans le systeme interaméricains des Drois de 1'Homme", en Cursos de Derechos Humanos de Donostia-San Sebastián, 10 (2009), pp. 89-110; Louise Mallinder. "The End of Amnesty or Regional Overreach? Interpreting the erosion of South America's Amnesty Laws, en International and Comparative Law Quarterly, (2016), disponible en: http://journals.cambridge.org/abstract_S0020589316000166; Michail Vagias, “ Revocation of Enduring Amnesties vs. Principles of Legality: Jurisprudential Contestations between the Inter- American Court of Human Rights and Domestic Courts", en Italian Yearbook of International Law, 26( 2016), pp. 107-137.
} 
leyes puedan ser consideradas compatibles con las disposiciones del CEDH ${ }^{22}$. No obstante, un análisis más en detalle nos muestra que si bien estas diferencias resultan evidentes en las primeras decisiones de los órganos europeos de protección, con el paso del tiempo irán desapareciendo y acabarán siendo más aparentes que reales.

Así, en el asunto Dujardin y otros v. Francia, que es el primer caso en el cual un órgano europeo entró a valorar una ley de amnistía, la Comisión se refirió a la posibilidad de que una ley de amnistía contravenga el CEDH si responde a una práctica general destinada a impedir sistemáticamente las actuaciones judiciales contra los autores de tales crímenes (asesinato), para desde aquí, concluir que: “ ....l'État est en droit d'adopter, dans le cadre de sa politique criminelle, les lois d'amnistie qu'il juge nécessaires à condition toutefois qu'un équilibre soit ménagé entre les intérêts légitimes d'un État et l'intérêt des justiciables à ce que le droit à la vie soit protégé par la loi'”23.

De lo anterior, se deduce que para la Comisión, criterios como la excepcionalidad, la finalidad de la medida y la ponderación entre los intereses del Estado y los derechos de los individuos resultan elementos claves a tener en cuenta para considerar, o no, compatible una ley de amnistía con el artículo 2 del $\mathrm{CEDH}^{24}$. No descartando, por tanto, la posibilidad de que, en ciertas circunstancias, dichas leyes pudieran ser compatibles con el Convenio.

Cabe indicar que esta posición asumida por la Comisión europea no va a guardar consonancia con la posición mantenida por aquella misma época por los órganos de protección del sistema interamericano y, más concretamente, por la CIDH. A este respecto, conviene recordar que unos pocos años antes, en concreto en 1986, la CIDH ya había exteriorizado su posición acerca de dichas leyes, indicando que "era un difícil problema a afrontar por las recientes democracias el de la investigación de las anteriores violaciones a los derechos humanos y la eventual sanción de sus responsables. Un problema sobre el que la Comisión (interamericana), así como cualquier otro órgano internacional, poco podía aportar; resultando que la respuesta debía emanar de los propios sectores nacionales afectados, que debían armonizar la urgencia de una reconciliación nacional y de una pacificación social con las ineludibles exigencias del conocimiento de la verdad y la justicia". Y a partir de ello, ofrecía solo como

${ }^{22}$ Véase al respecto Javier Chinchón Álvarez, "Las leyes de amnistía en el sistema europeo de derechos humanos. De la decisión de la Comisión en Dujardin y otros contra Francia a la sentencia de la Gran Sala en Margus contra Croacia: ¿progresivo desarrollo o desarrollo circular?, en Revista de Derecho Comunitario Europeo, 52 (2015), pp. 912-913.

${ }^{23}$ CEDH. Dujardin et autres c. France, núm. 16734/90, Decisión de la Comisión, 2 de septiembre de 1991, Decisions and Reports 72. Sobre los antecedentes de este caso, véase Chinchón Álvarez, op. cit., pp. 918-920.

${ }^{24}$ Sin embargo, la Comisión hizo notar que resultaba realmente imposible determinar el contenido de los mencionados criterios, por lo que se limitó a afirmar que a su juicio concurrían en el caso concreto, lo que le llevó a concluir de que no se había producido una vulneración de las disposiciones del CEDH. Ibid. 
un criterio adicional "la prohibición de lo que generalmente se conocen como «autoamnistías», es decir, las amnistías decretadas previamente por los propios responsables de las violaciones" 25 .

Este planteamiento inicial sería corregido al poco tiempo por la propia Comisión, quien adoptaría una postura más firme de rechazo a la posibilidad de que las leyes de amnistía pudieran ser compatibles con la CADH. Así, en un asunto relacionado con las masacres ocurridas en la zona de Las Hojas (El Salvador) en 1983, en la cual 74 personas fueron asesinadas por miembros de las fuerzas armadas de dicho país, contando con la colaboración de miembros paramilitares de la defensa civil, la Comisión sostuvo que la aplicación de Decreto de Amnistía salvadoreño de 1987 “constituye una clara violación de la obligación del Gobierno de El Salvador de investigar y sancionar las violaciones de los derechos de las víctimas de Las Hojas, y de proporcionar reparación de los daños producidos por la violación”. E indicó además que “...el referido Decreto de Amnistía, aplicado a este caso, impide la eficacia de un recurso jurídico sobre el asesinato, trato inhumano y la ausencia de garantías judiciales; niega el carácter fundamental de los derechos humanos más básicos. La Amnistía elimina la medida tal vez más efectiva para poner en vigencia tales derechos: el enjuiciamiento y castigo de los hechores"26.

Como puede apreciarse, en estos primeros momentos, la postura de los órganos europeos en el tema de leyes de amnistía no se correspondía con la posición de los órganos del sistema interamericano que ya por aquellos años entendían necesario introducir un escrutinio jurídico más severo a la hora de analizar la compatibilidad de dichas leyes con las disposiciones convencionales, lo que nos lleva a pensar que en aquel momento el diálogo entre ambos sistemas de derechos humanos era poco menos que inexistente ${ }^{27}$.

${ }^{25}$ CIDH, Informe Anual, 1985-1986, OEA/ Ser.L/V/II.68, doc. 8 rev. 1, 26 de septiembre de 1986, capítulo $\mathrm{V}$, párrs. 10-11.

${ }^{26} \mathrm{CIDH}$, Informe $n^{\circ}$ 26/92, Caso 10.287 (El Salvador), 24 septiembre de 1992, párrs. 15 -17. En otros asuntos de la misma época, la Comisión mantuvo que la cuestión no era tanto lo de la legitimidad interna de este tipo de leyes, ni tampoco las razones que se invocaban para justificarlas, sino que solamente se trataba de examinar si su contenido era incompatible, o no, con los derechos y garantías consagrados en la CADH. Al respecto, el elemento clave de análisis era el determinar si con ese tipo de leyes se pretendía cerrar toda posibilidad de iniciar o continuar los procesos judiciales, identificar a los autores y, en su caso, imponerles las sanciones penales correspondientes (véase CIDH , Informe $n^{\circ}$ 29/92, Casos 10.029, 10.036, 10.145, 10.305, 10.372, 10.373, 10.374 y 10.375 (Uruguay), 2 de octubre de 1992, párrs. 30-31 y CIDH, Informe $n^{\circ}$ 28/92, Casos 10.147, 10.181, 10.240, 10.262, 10309 y 10.311 (Argentina), 2 de octubre de 1992, párrs. 32, 33-34, 37, 39 y 41(Véase al respecto Neuman, “The External Reception...”, op. cit., p. 112). En el ámbito del sistema universal de las Naciones Unidas el estado de cosas no era muy distinto al interamericano. Así en 1992 el Comité de Derechos Humanos sostuvo que las amnistías son generalmente incompatibles con la obligación de los Estados de investigar graves violaciones a los derechos humanos, de garantizar que no se cometan tales actos y de velar por que no se realicen en el futuro (Comité de Derechos Humanos, Observación General núm. 20 sobre el art. 7 del Pacto Internacional de Derechos Civiles y Politicos, Doc. ONU HRI/GEN/1/Rev.1 at 30, 10 de marzo de 1992, párr. 15.).

${ }^{27}$ No es posible precisar con exactitud el motivo que llevaría a los órganos europeos de protección a evitar mencionar las decisiones de la CIDH en el tema de las amnistías. Más allá de las reticencias 
Con posterioridad a esta primera decisión, ha sido el TEDH quien ha abordado la temática de las leyes de amnistía en varios asuntos, si bien cabe advertir que éste nunca ha querido ofrecer más que algunos comentarios generales sobre esta cuestión. Las veces en las que el Tribunal sí se ha pronunciado, se empieza a percibir que su posición comienza a corresponderse con la de la Corte IDH, aunque todavía estamos en un momento en el cual no hay un cross-referencing jurisprudencial explícito entre tribunales.

La primera oportunidad en la que el Tribunal tuvo ocasión de efectuar un comentario general sobre el tema de las amnistías ocurrió en el caso Abdulsamet Yaman v. Turquía, en donde dijo lo siguiente: «The Court further points out that where a State agent has been charged with crimes involving torture or ill-treatment, it is of the utmost importance for the purposes of an 'effective remedy' that criminal proceedings and sentencing are not time-barred and that the granting of an amnesty or pardon should not be permissible" 28 .

En este pasaje el Tribunal se aparta claramente de lo afirmado antes por la Comisión europea en el caso Dujardin y otros respecto a las leyes de amnistía, ya que aquí no aparece ninguna mención a los elementos de juicio y ponderación esgrimidos en aquél asunto para poder validar, o no, una ley de amnistía. Al mismo tiempo, introduce una inédita fórmula verbal para referirse a que la concesión de una amnistía "no deberá ser permisible". Dicha fórmula ha sido interpretada de diversas formas en la doctrina: hay quien entiende que se trata de una mera recomendación o un consejo, en tanto que para otros se trata de una expresión que parece querer sugerir que las amnistías no serían posibles; o incluso hay quien ha sugerido que contiene una prohibición expresa de las mismas ${ }^{29}$.

Sea como fuera, lo cierto es que para el momento en que el Tribunal realizó dicho comentario, ya desde hacía algunos años la Corte IDH se había pronunciado en términos más enérgicos en torno a la prohibición de las amnistías. En aquellos años, en efecto, en un caso pionero, la Corte interamericana había sostenido que eran: “...inadmisibles las disposiciones de amnistía, las disposiciones de prescripción y el establecimiento de excluyentes de responsabilidad que pretendan impedir la investigación y sanción de los responsables de las violaciones graves de los derechos humanos" ${ }^{\prime 30}$.

a referirse a simples recomendaciones procedentes de un órgano de carácter no jurisdiccional, parece ser que la verdadera razón hay que encontrarla en el hecho de que se tratan de decisiones adoptadas en un contexto regional, como el de aquel momento en América Latina, caracterizado por violaciones graves y masivas de los derechos humanos, el cual no resultaba extrapolable al contexto europeo de aquellos años. En situaciones parecidas, los órganos europeos consideran que referirse a decisiones que no son específicas del contexto regional europeo no resultan útiles para la interpretación de las disposiciones del CEDH (Véase al respecto Forowicz "Factors influencing...", op. cit, pp. 209-210; Cheeseman, op. cit, p. 618).

${ }^{28}$ TEDH. Abdülsamet Yaman v. Turquía, № 32446/96, Sentencia de 2 de noviembre de 2004, párr. 55.

${ }^{29} \mathrm{Al}$ respecto, véase Chinchón Álvarez, op. cit., pp. 924-925.

${ }^{30}$ Corte IDH. Caso de Barrios Altos v. Perú, Fondo, Sentencia de 14 de marzo de 2001, Serie C n ${ }^{\circ}$ 75, párr. 41. Cabe indicar que un año antes, la propia Corte IDH había indicado que: "La Convención 
El comentario utilizado por el Tribunal en el asunto Abdulsmet Yaman se volvería a repetir, aunque con pequeñas variaciones, en otros asuntos similares, como el caso Okkall v. Turquía o en Yeter v. Turquía, en dónde se dijo que: "...when an agent of the State is accused of crimes that violate Article 3, the criminal proceedings and sentencing must not be time-barred and the granting of an amnesty or pardon should not be permisible ${ }^{31}$.

El examen de todos estos casos, nos lleva a coincidir con lo manifestado por Chinchón Álvarez en cuanto a que, "cuando menos respecto al art. 3 del $\mathrm{CEDH}^{32}$, parece posible sostener que la posición ya entonces mantenida por el Tribunal es que las leyes de amnistía no podrían ser admitidas"33. Un planteamiento que si bien no se corresponde exactamente con la posición más firme adoptada por la Corte IDH, sí que empieza a guardar ciertas similitudes con ella en lo que respecta a la consideración de que las amnistías resultan prohibidas en el caso de violaciones graves de los derechos humanos.

Tras estos casos, el Tribunal tuvo oportunidad de definir su posición en torno a las leyes de amnistía en el asunto Ould Dah v. Francia, ya que el núcleo central de este caso estaba relacionado directamente con dicha temática. En aquella ocasión, el Tribunal dijo: "Admittedly, the possibility of a conflict arising between, on the one hand, the need to prosecute criminals and, on the other hand, a country's determination to promote reconciliation in society cannot, generally speaking, be ruled out. In any event, no reconciliation process of this type has been put in place in Mauritania. However, as the Court has already observed, the prohibition of torture occupies a prominent place in all international instruments relating to the protection of human rights and enshrines one of the basic values of democratic societies. The obligation to prosecute criminals should not therefore be undermined by granting impunity to the perpetrator in the form of an amnesty law that may be considered contrary to international law $w^{34}$.

\footnotetext{
Americana garantiza que toda persona sujeta a la jurisdicción de un Estado tiene la posibilidad de acudir ante la justicia para hacer valer sus derechos y asimismo impone a los Estados la obligación de prevenir, investigar, identificar y sancionar a los autores intelectuales y encubridores de violaciones de los derechos humanos. Los Estados no pueden, para no dar cumplimiento a sus obligaciones internacionales, invocar disposiciones existentes en su derecho interno, como lo es en este caso la Ley de Amnistía expedida por el Perú, que a juicio de esta Corte, obstaculiza la investigación y el acceso a la justicia. Por estas razones, el argumento del Perú en el sentido de que le es imposible cumplir con ese deber de investigar los hechos que dieron origen al presente caso debe ser rechazado". Corte IDH. Caso Loayza Tamayo v. Perú, Reparaciones, Sentencia de 27 de noviembre de 1998, en Serie C nº. 42, párr. 168 .

31 TEDH. Okkall v. Turquía, $\mathrm{n}^{\circ}$ 52067/99, 17 de octubre de 2006, párr. 76; y TEDH. Yeter v. Turquía, no $33750 / 03$, de 8 de abril de 2008, párr.70 (cursivas añadidas).

32 Art. 3. "Nadie podrá ser sometido a tortura ni a penas o tratos inhumanos o degradantes".

${ }_{33}$ Chinchón Álvarez, op. cit., p. 928.

34 TEDH. Ould Dah v. Francia, no 13113/03, 17 de marzo de 2009, p. 17; las cursivas son nuestras. Sobre los antecedentes generales de este caso, véase Chinchón Álvarez, op. cit, pp. 928-930.
}

Araucaria. Revista Iberoamericana de Filosofía, Política, Humanidades y Relaciones Internacionales, año 20, $\mathrm{n}^{\circ} 40$ Segundo semestre de 2018. Pp. 577-604. ISSN 1575-6823 e-ISSN 2340-2199 doi: 10.12795/araucaria.2018.i40.24 
De lo dicho por el Tribunal en el citado párrafo no queda del todo claro cuál es exactamente su posición en relación con el tema de las amnistías: si tan solo está exponiendo una posible y general reflexión, o si es que a su juicio si Mauritania hubiera realizado un auténtico «proceso de reconciliación" nacional, podría entonces haberse aprobado una ley de amnistía general incluso para las más graves violaciones a los derechos humanos, asegurando de esta forma también la completa impunidad por esos hechos ${ }^{35}$.

Lo cierto es que este último argumento resulta difícil de sostener jurídicamente toda vez que ello plantearía no pocos problemas si se tiene en cuenta que ya para aquel entonces existía un extendido consenso entre los órganos internacionales de derechos humanos en cuanto a la prohibición de las amnistías. De ahí que se haya indicado que, en el antedicho párrafo, el Tribunal se está refiriendo en realidad a la incompatibilidad de las leyes de amnistía con el CEDH, alineándose así con la posición mantenida por los demás órganos de protección, y también por la Corte IDH, aunque manteniendo quizá un matiz propio $^{36}$. Una interpretación distinta de lo dicho por el Tribunal hubiese supuesto chocar con la posición mayoritaria adoptada por dichos órganos en esta temática.

En suma, la valoración que hace el Tribunal en Ould Dah v. Francia del tema de las amnistías podría entenderse como una evolución en la posición mantenida por los órganos europeos de protección de derechos humanos, al reconocerse por primera vez la incompatibilidad de dichas leyes con el CEDH cuando impidan el cumplimiento efectivo de las obligaciones previstas en sus arts. 2 y $3^{37}$. En la asunción de este planteamiento queda claro que Tribunal no ha decidido en un vacío, sino que ha tenido muy en cuenta diversas fuentes externas y, dentro de ellas, aunque sin mencionarla explícitamente, la jurisprudencia de la Corte IDH, habida cuenta que desde el emblemático caso Barrios Altos $v$. Perú de 2001, éste case law ha sido considerado como todo un referente entre los órganos internacionales de protección ${ }^{38}$. Por todo ello nos parece que la falta de mención expresa a dicha jurisprudencia por el Tribunal europeo no significa automáticamente que éste la haya ignorado, ya que todo apunta a que sí la tuvo en cuenta, dado que era el case law internacional de referencia en esta temática, pero sin reconocerlo expresamente en sus decisiones ${ }^{39}$. Cierto es que

\footnotetext{
${ }^{35}$ Ibid, p. 932.

36 Véase Eva Brems, "Transitional Justice in the Case Law of the European Court of Human Rights”, en The International Journal of Transitional Justice, 2 (2011), p. 292.

${ }_{37}$ Chinchón Álvarez, op. cit., p. 936.

38 Esta evolución en la posición del Tribunal en torno al tema de las amnistías puede explicarse en razón de la necesidad que tiene éste de actualizar y mejorar el significado de las disposiciones del $\mathrm{CEDH}$ en esta temática, lo que lo lleva a armonizar su posición con la mantenida por los restantes órganos internacionales de protección de derechos humanos (Véase al respecto, Forowicz "Factors influencing...”, op. cit., pp. 194-197 y 211-212).

39 Cheeseman, op. cit., pp. 603-604.
}

Araucaria. Revista Iberoamericana de Filosofia, Política, Humanidades y Relaciones Internacionales, año 20, $\mathrm{n}^{\circ} 40$ Segundo semestre de 2018. Pp. 577-604. ISSN 1575-6823 e-ISSN 2340-2199 doi: 10.12795/araucaria.2018.i40.24 
esto último resulta insuficiente para hablar de la existencia de un diálogo entre tribunales, pero bien pudiera tratarse del punto de partida para el inicio de un diálogo en esta temática.

\section{B. EI diálogo judicial entre el TEDH y la Corte IDH en el tema de leyes de amnistía: un ejemplo de cross-fertilization entre tribunales de derechos humanos}

En este apartado del trabajo nos centraremos en el análisis de las decisiones más recientes del Tribunal en el tema de leyes de amnistía, y en dónde tendremos ocasión de comprobar que se ha producido un cambio sensible en la posición del Tribunal en relación con el período anterior, y cómo en este hecho ha tenido mucho que ver la influencia ejercida por las decisiones de su contraparte interamericana, especialmente de aquellas que con el paso del tiempo se han convertido en leading cases en la materia ${ }^{40}$.

La primera mención directa a la jurisprudencia interamericana la vamos a encontrar en el asunto de Lexa v. Slovakia ${ }^{41}$. En este caso el Tribunal sostuvo que la obligación de investigar, especialmente en casos en los que la pérdida de vida $u$ otras formas de malos tratos pueda ser atribuida a agentes del Estado, excluye la posibilidad de que el Estado conceda amnistías para proteger a dichos agentes de ser juzgados por violaciones de derechos humanos. Para apoyar sus argumentos el TEDH hizo una breve referencia, en el apartado de la sentencia dedicado a examinar el "Derecho internacional y la práctica", a dos sentencias de la Corte IDH. Nos referimos a los casos de Barrios Altos y otros v. Perú y el de Bulacio v. Argentina ${ }^{42}$. La mención a estas dos decisiones le van servir al Tribunal para un mejor conocimiento del contexto jurídico del caso, y más específicamente para confirmar la tendencia general en el Derecho internacional que prohíbe las amnistías irrestrictas frente a graves violaciones de los derechos humanos ${ }^{43}$.

Pese a que en este caso las referencias a la jurisprudencia de la Corte IDH sólo le sirvieron al TEDH para informarse sobre el estado actual del tema de las amnistías en el Derecho Internacional, sin que hayan tenido incidencia en

${ }^{40}$ Este análisis lo haremos tomando en cuenta el Informe de 2016 de citas de la jurisprudencia de la Corte IDH por el TEDH . Vid. "References to the Inter-American Court of Human Rights", cit.

${ }^{41}$ TEDH. Lexa v. Slovakia, $n^{\circ} 54334 / 00$, de 23 de septiembre de 2008. Este caso está relacionado con la amnistía concedida un agente de seguridad del Estado implicado en el secuestro del hijo del antiguo Presidente del país.

${ }^{42}$ En relación con el Caso de Barrios Altos, el Tribunal reprodujo íntegramente el célebre pasaje de dicha sentencia (vid. supra, p. 30). Mientras que en el Caso de Bulacio citó textualmente la parte de la sentencia que dice “...son inadmisibles las disposiciones de prescripción o cualquier obstáculo de derecho interno mediante el cual se pretenda impedir la investigación y sanción de los responsables de las violaciones de derechos humanos". Corte IDH, Caso Bulacio v. Argentina, Sentencia de 18 de septiembre de 2003 (Fondo, Reparaciones y Costas), párr. 116.

${ }^{43}$ Véase Garlicki, op. cit., p. 63; García Roca, op. cit, p. 557; Neuman “The External Reception...”, op. cit. , p. 114.

Araucaria. Revista Iberoamericana de Filosofía, Política, Humanidades y Relaciones Internacionales, año 20, $n^{\circ} 40$. Segundo semestre de 2018. Pp. 577-604. ISSN 1575-6823 e-ISSN 2340-2199 doi: 10.12795/araucaria.2018.i40.24 
la motivación de su decisión final, no es posible ignorar la creciente influencia que empieza a tener éste case-law -y sobre todo el emblemático Caso Barrios Altos- sobre el Tribunal europeo en esta temática, lo que nos sitúa ante un claro ejemplo de diálogo "encubierto" entre tribunales ${ }^{44}$.

El segundo caso que se menciona en el mencionado Informe es la Sentencia (Gran Sala) en el asunto de Margus v. Croacia, el cual se ha convertido, como veremos, en el caso emblemático de cross-fertilization jurisprudencial entre el TEDH y la Corte IDH en el tema de leyes de amnistía. No obstante, antes de analizar dicha sentencia, conviene conocer previamente la decisión de "Sala" en este asunto ${ }^{45}$, ya que si bien dicha decisión no es mencionada en el Informe, en ella podemos encontrar varias referencias a decisiones y jurisprudencia del sistema interamericano en el tema de las amnistías, algunas de las cuales sería también mencionadas en la sentencia de "Gran Sala". En concreto, la "Sala" se refirió a varios informes y decisiones de la CIDH en relación con la situación en El Salvador ${ }^{46}$, así como al ya mencionado Caso Barrios Altos ${ }^{47} \mathrm{e}$ incluso se recoge lo expresado por el juez Cançado Trindade en dicho asunto ${ }^{48}$. Todas estas referencias interamericanas, junto a las de otros de otros órganos y tribunales internacionales, le van a servir a la "Sala" para afirmar que desde hace décadas existe una clara y constante tendencia que determina que la concesión de amnistías en casos de graves violaciones de derechos humanosque incluyen crímenes contra la humanidad, crímenes de guerra y el genocidioestá prohibida por el Derecho internacional ${ }^{49}$.

Teniendo en cuenta lo anterior, la Sala va a concluir que no se había producido una violación del art. 4 del Protocolo $\mathrm{N}^{\mathrm{0}} 7$ al Convenio Europeo (principio ne bis in idem) ${ }^{50}$, por cuanto la concesión de amnistía al denunciante respecto de actos que se podían caracterizar como crímenes de guerra contra la

${ }^{44}$ Sobre la noción de "diálogo encubierto" vid. supra nota 11.

45 TEDH. Margus v. Croacia (S), núm. 445/10, 13 de noviembre de 2012. Sobre este caso véase Elizabeth Stubbins Bates, E., "Introductory note to Marguš v. Croatia (EUR.CT. H.R.)", en International Legal Materials, 5 (2014), pp. 751-809.

${ }^{46}$ En concreto, el Tribunal valoró el Caso 10.287 (El Salvador), Informe n²6/92, de 24 de septiembre de 1992, párr. 2; al "Informe sobre la situación de los Derechos Humanos en El Salvador", Doc. OEA/Ser. L/V/II. 85 Doc. 28 Rev.,de 11 de febrero de 1994, párr. 58; y al Caso 10. 480, Informe No 1/99, de 27 de enero de 1999, párrs.. 112, 115,123 y 129 así como también a las conclusiones de la CIDH en este asunto.

${ }^{47}$ Caso Barrios Altos v. Perú, op. cit., párrs. 41, 42, 43 y 44.

${ }^{48} \mathrm{Ibid}$, Voto concurrente del Juez Antonio Augusto Cançado Trindade, párr. 13.

${ }^{49}$ Cabe indicar que la propia "Sala" reconoció esto último cuando sostuvo que: "this undestanding is drawn from customary rules of international humanhitarian law, human rights treaties, as well as decisions of international and regional courts and developing State practice..." (Margus v. Croacia (S), op. cit., párr. 74; cursivas son nuestras).

${ }_{50}$ Art. 4.1. Nadie podrá ser inculpado o sancionado penalmente por un órgano jurisdiccional del mismo Estado, por una infracción de la que ya hubiere sido anteriormente absuelto o condenado en virtud de sentencia definitiva conforme a ley y al procedimiento penal del Estado. 2. Lo dispuesto en el anterior párrafo no impedirá la reapertura del proceso, conforme a ley y al procedimiento penal del Estado interesado, si hechos nuevos o nuevas revelaciones o un vicio esencial en el proceso anterior pudieran afectar a la sentencia dictada.

Araucaria. Revista Iberoamericana de Filosofia, Politica, Humanidades y Relaciones Internacionales, año 20, $\mathrm{n}^{\circ} 40$ Segundo semestre de 2018. Pp. 577-604. ISSN 1575-6823 e-ISSN 2340-2199 doi: 10.12795/araucaria.2018.i40.24 
población civil equivalía a un defecto fundamental en el procedimiento, y por tanto se cumplían las condiciones que exigía el párrafo 2 del referido precepto para reabrir el procedimiento ${ }^{51}$. Esta sentencia, en suma, viene a corroborar la notable influencia que ha ejercido la jurisprudencia de la Corte IDH sobre el TEDH en el tema de leyes de amnistía, y de que éste último se refiere a dicha jurisprudencia para darle mayor consistencia y solidez a sus decisiones en esta temática. De este modo, empiezan a existir puntos más que notables de convergencia en la jurisprudencia de ambos tribunales derechos humanos en relación con dichas leyes, algo que, como veremos a continuación, se va a ver confirmado tras la sentencia de "Gran Sala".

Por lo que respecta a la sentencia de "Gran Sala" 52 , ésta va a ser mucho más prolija en la mención que hace de las decisiones y jurisprudencia del sistema interamericano de derechos humanos, ya que no sólo reproduce las recogidas en la sentencia de "Sala", sino que incorpora además una serie de casos de la Corte IDH no mencionados antes ${ }^{53}$. Se tratan todos ellos de los casos más representativos de la jurisprudencia americana en el tema de amnistías, alguno de los cuales es considerado como un leading case en la materia ${ }^{54}$.

En dicha sentencia, el Tribunal, al valorar si el art. 4 del Protocolo 7 al CEDH resultaba aplicable en las circunstancias específicas del caso, en los que se había concedido al denunciante una amnistía incondicional en relación a actos equivalentes a graves violaciones de derechos humanos ${ }^{55}$, expuso en primer término cuál era la posición del Convenio al respecto, luego precisó la

${ }^{51}$ Margus v. Croacia (S), op. cit., párr. 73. Ésta decisión de "Sala" puede entenderse como una confirmación por parte del Tribunal de que no son posibles las amnistías frente a graves violaciones de los derechos humanos.

${ }^{52}$ Margus v. Croacia (GS), núm. 4455/10, de 27 de mayo de 2014.

${ }_{53}$ Entre éstos hay que mencionar la valoración de los Casos de Almonacid Arellano y otros v. Chile ( Serie $\mathrm{C}, \mathrm{n}^{\circ} 154$, Excepciones preliminares, Fondo, Reparaciones y Costas, Sentencia de 26 de septiembre de 2006) del cual se cita íntegramente los párrafos 154-155; La Cantuta v. Perú ( Fondo, Reparaciones y Costas, Sentencia de 29 de noviembre de 2006, Serie $\mathrm{C} \mathrm{n}^{\circ} 162$ ) del cual se cita literalmente los párrafos 151-154; Anzualdo Castro v. Perú, (Excepciones preliminares, Fondo, Reparaciones y Costas, Serie $\mathrm{C}, \mathrm{n}^{\circ}$ 202) del cual se cita textualmente el párrafo 182; Gelman v. Uruguay (Fondo y Reparaciones, Sentencia de 24 de febrero de 2011, Serie C, $\mathrm{n}^{\circ}$ 221) del cual se cita íntegramente los párrafos 184, 189-191, 195-206, 209-214, 225-229 y 240; Gomes Lund y otros ( "Guerrilha do Araguaia”) v. Brasil (Excepciones preliminares, Fondo, Reparaciones y Costas, Sentencia de 24 de noviembre de 2010, Serie $\mathrm{C} \mathrm{n}^{\circ} 219$ ) del cual se cita textualmente los párrafos 171, 172, 175 y 176; y, Masacres de El Mozote y lugares aledaños v. El Salvador (Fondo, Reparaciones y Costas, Sentencia de 25 de octubre de 2012, Serie $\mathrm{C} \mathrm{n}^{\circ} 252$ ), del cual se cita textualmente los párrafos 283-286.

${ }^{54}$ En relación con las denominadas "autoamnistías" o "amnistías autocondedidas", esto es leyes de amnistía que se otorgan a sí mismos y a todos los agentes del Estado los responsables políticos de los gobiernos donde se ha violado de forma sistemática los derechos humanos, tienen la consideración de leading cases los Casos de Barrios Altos, Almonacid Arellano Gomes Lund, y Gelman. Mientras que en el caso de las denominadas "amnistías negociadas", esto es las que surgen tras un conflicto armado y bajo el pretexto de alcanzar la reconciliación nacional, dicha consideración la tiene el más reciente caso de Masacres de El Mozote. (véase al respecto, José Esteve Moltó, "La jurisprudencia de la Corte Interamericana de Derechos Humanos ante las leyes de amnistía: un referente para la necesaria "fertilización" trasatlántica", en Eunomía, Revista en Cultura de la Legalidad, 9 (2016), pp. 105-123).

55 Margus v. Crocia (GS), op. cit., párr. 123. 
postura en virtud del Derecho Internacional, para finalmente, y sobre la base de lo anterior, formular su conclusión final. En lo que respecta a la posición del Convenio, el Tribunal empezó recordando que en su jurisprudencia se había determinado que la concesión de una amnistía respecto a asesinatos y malos tratos a los civiles era contraria a las obligaciones del Estado en virtud de los artículos 2 y 3 del CEDH, pues podría obstaculizar la investigación de tales delitos y necesariamente conducir a la impunidad de los responsables. Tal resultado, según el Tribunal, disminuiría el objeto de la protección garantizada por dichos artículos, que son además los más fundamentales dentro de la $\mathrm{CEDH}$, y haría ilusoria las garantías en lo que respecta al derecho individual a la vida y el derecho a no ser objeto de malos tratos. Recordando además que el objeto y fin del CEDH exige que sus disposiciones sean interpretadas y aplicadas a fin lograr una protección práctica y efectiva ${ }^{56}$.

Tras realizar dichas afirmaciones, se indicó que si bien el presente caso no estaba relacionado con violaciones de los artículos 2 y 3 de la CEDH, sino con la del artículo 4 del Protocolo $\mathrm{N}^{\circ} 7$, era necesario realizar una lectura conjunta de la Convención y sus Protocolos, y de que, por tanto, las garantías bajo el artículo 4 del Protocolo $\mathrm{N}^{\mathrm{o}} 7$ y las obligaciones de los Estados bajo los artículos 2 y 3 debían considerarse como partes de un todo ${ }^{57}$.

Por su parte, en su análisis de la posición en virtud del Derecho Internacional, el Tribunal recordó que la Convención y sus Protocolos no pueden interpretarse en un vacío, sino que habrá que hacerlo en consonancia con los principios del Derecho Internacional, queriendo indicar con ello que, su interpretación de la compatibilidad de las leyes de amnistía con la Convención en el caso concreto, se haría de acuerdo con lo establecido en dicho ordenamiento jurídico ${ }^{58}$. En tal sentido, en el apartado de la sentencia dedicado a los "Relevant International Law Materials", se recoge una amplia relación de convenios y pronunciamientos de tribunales y organismos internacionales, entre los que destaca la mención que se hace a las decisiones de los órganos interamericanos de protección y, particularmente, a los de la Corte $\mathrm{IDH}^{59}$. Especialmente relevante resulta la referencia al caso de Masacres de El Mozote, pues dicho caso tendrá una influencia decisiva en la decisión final del Tribunal en este asunto ${ }^{60}$.

Entrando en sus valoraciones sobre la posición del Derecho internacional, la Gran Sala se centró en el análisis del artículo 6.5 del Protocolo II adicional a las Convenciones de Ginebra, en relación con la protección de las víctimas

${ }^{56}$ Ibid., párr. 127.

${ }^{57}$ Ibid., párr. 128.

${ }^{58}$ Ibid., párr. 129.

${ }^{59}$ Véase supra, notas 40 y 51.

${ }^{60}$ Dicha relevancia ha sido reconocida por el propio Tribunal ("References to the Inter- American Court...", op. cit, p. 32). Sobre los detalles de esta masacre, véase Rufina Amaya, Mark Danner, M. y Carlos Henríquez, Luciérnagas en El Mozote, San Salvador, Ediciones Museo de la Palabra y la Imagen, 2014, pp. 16-156.

Araucaria. Revista Iberoamericana de Filosofia, Politica, Humanidades y Relaciones Internacionales, año 20, $\mathrm{n}^{\circ} 40$. Segundo semestre de 2018. Pp. 577-604. ISSN 1575-6823 e-ISSN 2340-2199 doi: 10.12795/araucaria.2018.i40.24 
de los conflictos armados internos, que dice: "A la cesación de las hostilidades, las autoridades en el poder procurarán conceder la amnistía más amplia posible a las personas que hayan tomado parte en el conflicto armado.... ${ }^{61}$ ". Y ello por cuanto, en el caso examinado, la amnistía había sido concedida por hechos cometidos en el contexto de un conflicto interno. Por ello, el Tribunal estimó pertinente analizar la compatibilidad de dicha ley con las obligaciones derivadas del CEDH a la luz de lo establecido en el referido Protocolo.

En su análisis el Tribunal va a tener en cuenta la interpretación que hace de dicho precepto la CorteIDH en el Caso de Masacres de El Mozote, que excluye su aplicación respecto a los autores de crímenes de guerra y crímenes de lesa humanidad $^{62}$. Y que el fundamento de dicha conclusión hay que encontrarlo, de acuerdo con la Corte americana, en las obligaciones de los Estados en virtud del Derecho internacional, de investigar y sancionar los crímenes de guerra. Es lo que va a llevar a dicha Corte a concluir que "las personas sospechosas o acusadas de haber cometido crímenes de guerra no pueden ser objeto de amnistía". Esta interpretación del artículo 6.5, le va a permitir al Tribunal declarar obiter dictum que la misma obligación de investigar y enjuiciar existe con respecto a las violaciones graves de los derechos humanos y que, por lo tanto, las amnistías previstas en dicho precepto tampoco resultan aplicables a dichos actos ${ }^{63}$.

Asimismo, en su referencia a la práctica internacional, el Tribunal volvió a citar nuevamente los casos más emblemáticos de la jurisprudencia de la Corte IDH en el tema de amnistías, como los Casos Barrios Altos, Gomes Lund y otros, Gelman y Masacres de El Mozote y lugares aledaños, en los cuales el órgano interamericano adoptó una postura más firme, al considerar que no podía aceptarse ninguna amnistía en casos de graves violaciones de derechos humanos, por cuanto ello perjudicaría gravemente el deber de los Estados de investigar y sancionar a los responsables de dichos actos ${ }^{64}$. Destacando además que la propia Corte IDH había determinado que este tipo de amnistías resultaban totalmente contrarias a los derechos reconocidos en el $\mathrm{DIDH}^{65}$.

Tras este análisis previo, caracterizado, como acabamos de ver, por las continuas referencias al case law de la Corte $\mathrm{IDH}^{66}$, el Tribunal va a formular

${ }^{61}$ Art. 6.5 del Protocolo Adicional a los Convenios de Ginebra de 12 de agosto de 1949 relativo a la protección de las víctimas de los conflictos armados sin carácter internacional (Protocolo II). Ginebra, 8 de junio de 1977. Su entrada en vigor se produjo el 7 de diciembre de 1978.

${ }^{62}$ Caso de Masacres de El Mozote y lugares aledaños, op. cit., párr. 286

${ }^{63}$ Margus v. Croacia (GS), op. cit. párr. 131.

${ }^{64}$ En este punto el Tribunal citó directamente los casos de Gelman v Uruguay, op. cit, párr. 195 y Gomes Lund y otros v. Brasil, op. cit., párr.. 171

${ }^{65}$ Para respaldar dicha afirmación el Tribunal se apoyó expresamente en el caso de Gomes Lund y otros v. Brasil, op. cit, párr. 172.

${ }^{66}$ Lo que confirma la fuerte influencia que tuvo el case law interamericano en la decisión final en este caso, pues las únicas "fuentes externas" que examina in extenso el Tribunal en esta parte de la sentencia son los leading cases de la Corte IDH y no otros instrumentos y decisiones internacionales 
sus conclusiones finales, las que podríamos dividir en dos partes. En una primera parte, el Tribunal concluyó diciendo que existe "una tendencia cada vez mayor en el Derecho internacional de considerar a las amnistías concedidas en casos de graves violaciones de derechos humanos como incompatibles con la obligación reconocida unánimemente de enjuiciar y sancionar a los responsables de dichas graves violaciones" ${ }^{167}$. Queriendo indicar con ello que ésta era la posición seguida abrumadoramente por los órganos de derechos humanos y que, en esa medida, era la posición que había tenido en cuenta en su análisis de la compatibilidad de las leyes de amnistía con el CEDH. Este pasaje resulta clave dentro de la sentencia pues el Tribunal está reconociendo, aun sin mencionarlo expresamente, pues ya lo ha hecho en los párrafos precedentes, el fuerte influjo que tiene el case law interamericano en todo lo referente al tema de leyes de amnistía ${ }^{68}$.

En la segunda parte de sus conclusiones, el Tribunal introdujo inopinadamente un párrafo no previsto en la sentencia de Sala, el cual ha suscitado ciertas dudas en cuanto a qué es lo que quiso decir exactamente el Tribunal y si ello suponía alejarse de su anterior planteamiento. En concreto, el Tribunal dijo: "Incluso si se aceptara que las amnistías son posibles cuando existen circunstancias particulares, como un proceso de reconciliación y una forma de compensación a las víctimas, la amnistía concedida al denunciante en el presente caso seguiría sin ser aceptable ya que nada indica que hayan concurrido tales circunstancias" $"$. De una primera lectura de este párrafo, pudiera parecer que el Tribunal estaría volviendo a lo sostenido en Ould Dah, o incluso Dujardin y otros, en el sentido de considerar la posibilidad de que, bajo determinadas circunstancias, las amnistías pudieran ser compatibles con el CEDH. Un planteamiento hasta cierto punto sorprendente, si se tiene en cuenta que el Tribunal ya había definido en el párrafo anterior su postura en torno a este tema. En todo caso, hay que advertir que cuando el Tribunal realiza dichas afirmaciones no lo hace en términos definitivos sino que en todo momento se está expresando en términos hipotéticos Esta utilización de un lenguaje probabilístico, ha llevado a un sector doctrinal a estimar que lo dicho en el citado párrafo no tiene, o al menos parece tener, la entidad suficiente como para modificar la conclusión general de que para el Tribunal las leyes de amnistía

citados antes por el propio TEDH. Algo hasta cierto punto sorprendente, ya que en el case law europeo las referencias a la jurisprudencia americana siempre habían venido acompañadas de citas a esa otra práctica internacional.

${ }^{67}$ Margus v. Croacia (GS), op. cit, párr. 139.

${ }^{68}$ Veáse al respecto, Oscar Parra-Vera, "Algunos aspectos procesales y sustantivos de los diálogos recientes entre la Corte Interamericana de Derechos Humanos y el Tribunal Europeo de Derechos Humanos" [en Pablo Santolaya Marchetti e Isabel Wences, coords., La América de los Derechos, Madrid, Centro de Estudios Constitucionales, 2016], pp. 580-582

${ }^{69}$. Margus v. Croacia (GS), op.cit, párr.139

Araucaria. Revista Iberoamericana de Filosofia, Politica, Humanidades y Relaciones Internacionales, año 20, $\mathrm{n}^{\circ} 40$. Segundo semestre de 2018. Pp. 577-604. ISSN 1575-6823 e-ISSN 2340-2199 doi: 10.12795/araucaria.2018.i40.24 
son contrarias a las obligaciones contenidas en los arts. 2 y 3 del $\mathrm{CEDH}^{70}$, siendo ésta su posición "oficial".

De hecho, éste argumento sería decisivo para que, en el presente caso, el Tribunal concluyese que al formular un nuevo auto de acusación contra el denunciante y condenarlo por crímenes de guerra contra la población civil, las autoridades croatas respetaron el CEDH y el Derecho internacional, razón por la cual se declaró el caso inadmisible ${ }^{71}$.

No obstante, subsiste la duda de por qué el Tribunal introdujo el citado párrafo en sus conclusiones finales. Al respecto, se ha dicho que su inclusión respondería a una fórmula de compromiso utilizada para alcanzar un texto en el que no tuviera que descartar de forma directa los argumentos expresados por tres jueces del Tribunal en su Voto concurrente y lo sostenido en la fase escrita del proceso por un grupo de académicos en su condición de terceros intervinientes, sobre cuál debería ser su posición del Tribunal en este tema ${ }^{72}$. Pero que en realidad lo indicado en el párrafo en cuestión no altera para nada la que ha sido la posición reiterada y constante del Tribunal.

Sea como fuera, interesa conocer cuáles fueron los argumentos jurídicos esgrimidos por el grupo de académicos y los jueces en su Voto concurrente que hicieron necesario que el Tribunal introdujese la fórmula de compromiso antes indicada. Así, en un documento titulado The International Legal Status of Amnesties, el grupo de académicos mantuvo que no era posible establecer una prohibición absoluta de aprobar una ley de amnistía, aun cuando ésta consagrara la plena impunidad de los responsables de graves violaciones de derechos humanos, si ello representaba el único camino para poner fin a un régimen no democrático o a un conflicto armado que se prolonga indefinidamente en el tiempo ${ }^{73}$. Para respaldar dicha afirmación, se va a hacer mención no sólo a decisiones internas de tribunales nacionales sino también a la jurisprudencia de la Corte IDH. En este punto, se indicó que en el seno de la Corte IDH se había matizado o debilitado la que había sido la posición tradicional de éste órgano en relación con el tema de las leyes de amnistía, citándose en concreto lo acontecido en el Caso de Masacres de El Mozote, en donde el Presidente de la Corte y otros cuatro magistrados sugirieron la posibilidad de que, aun tratándose de supuestos de graves violaciones de derechos humanos, la obligación de investigar y sancionar a los responsables de dichos hechos no era absoluta y tenía que ponderarse en relación con los requerimientos de una

70 Veáse Chinchón Álvarez, op cit., pp. 941-942

${ }^{71}$ Parra-Vera, op. cit, pp. 581-582.

72 Chinchón Álvarez, op. cit., p. 946.

${ }^{73}$ Margus v. Croacia (GS), op. cit, párr.113 Este tipo de planteamientos suelen responder a lo que comúnmente se conoce, en el marco de los amplios debates sobre la justicia transicional, como posturas "realistas" o "pragmáticas", sustentadas generalmente en consideraciones políticas o propias de las "exigencias negociadoras" antes que en argumentos jurídicos estrictamente hablando (Chinchón Álvarez, op. cit, p. 942).

Araucaria. Revista Iberoamericana de Filosofía, Política, Humanidades y Relaciones Internacionales, año 20, $n^{\circ} 40$. Segundo semestre de 2018. Pp. 577-604. ISSN 1575-6823 e-ISSN 2340-2199 doi: 10.12795/araucaria.2018.i40.24 
paz negociada y reconciliación en el marco de situaciones de post- conflicto $\operatorname{armado}^{74}$. Estas inconsistencias de la referida sentencia serían aprovechadas en el citado Informe para hacer notar que la autoridad de la Corte en el tema de leyes de amnistía se habría visto debilitada e indicarían que ésta habría modificado su valoración acerca de dichas leyes, apartándose así de su anterior jurisprudencia. Por su parte, los jueces Sikuta, Wojtyczek y Vehabovic, en su Voto concurrente, se identificaron plenamente con lo expresado por los académicos en cuanto a la posibilidad de que, bajo ciertas circunstancias, habría argumentos de índole práctica para conceder una amnistía en casos de violaciones graves de los derechos humanos ${ }^{75}$.

Sin pretender entrar en un debate acerca de la justificación de algún tipo de amnistía en situaciones de post-conflicto, lo que desbordaría ampliamente nuestro ámbito de estudio ${ }^{76}$, sí que conviene dejar en claro, y ello pese a la polémica causada por el sentido del Voto de varios de sus jueces, que en la sentencia en el Caso de El Mozote y lugares aledaños la Corte IDH no sólo no modificó su valoración en torno a las leyes de amnistía sino que se reafirmó en su jurisprudencia anterior ${ }^{77}$, por lo que difícilmente puede citarse este caso como el inicio de un cambio en el case law del órgano interamericano ${ }^{78}$. Esto

${ }^{74}$ Ver el Voto Concurrente del Juez Diego García- Sayán en el Caso de Masacres de El Mozote y lugares aledaños, op. cit, especialmente los párrs. 4 y 37-38. A este voto se van a adherir los jueces Leonardo Franco, Margarette May Macaulay, Rhadys Abreu Blondet y Alberto Pérez Pérez. De este Voto concurrente resulta difícil de explicar por qué si la opinión mayoritaria (cinco de siete jueces) era favorable a ese "juicio de ponderación" en el contexto de un proceso de transición tras un conflicto armado, no se incluyó dicha opinión en el cuerpo principal de la sentencia y se dejara de forma marginal en un Voto concurrente. Pero sobre todo llama la atención el cuestionamiento que se hace del carácter absoluto de la obligación de investigar y sancionar a los responsables de graves violaciones de derechos humanos, dado que éste ha sido el argumento principal en torno al cual la Corte ha sustentado la inadmisibilidad de las amnistías. Lo que ha llevado a algún autor a preguntarse si, tras este caso, el nuevo paradigma en la valoración de las amnistías sería el de la "ponderación" de la paz (Esteve Moltó, op. cit., pp. 115-118).

${ }^{75}$ En concreto, dichos jueces se refirieron a que: "We cannot rule out the possibility that such an amnesty might in some instances serve as a tool enabling an armed conflict or a political regime that violates human rights to be brought to an end more swiftly, thereby preventing further violations in the future" ( Joint Concurring Opinion of Judges Sikuta, Wojtyczek y Vahabovic, párr.9); reconociendo, no obstante, que en las últimas décadas el margen de maniobra de los Estados para aprobar dichas leyes se habría reducido notablemente.

${ }^{76}$ Sobre los términos de este debate véase Louise Mallinder, Amnesty, Human Rights and Political Transitions. Bridging the Peace and Justice, Oxford, Hart Publishing, 2008, pp. 1-598; Vera Vriezen, Amnesty Justified? The need for a case by case approach in the interests of human rights, Cambridge, Intersentia Ltd., 2012, pp. 39-58; Javier Dorado Porras, "Justicia transicional, persecución penal y amnistías" en Derechos y Libertades. Revista del Instituto Bartolomé de las Casas, 28 (2013), pp. $81-113$.

${ }_{77}$ Caso de Masacres de El Mozote y lugares aledaños, op. cit., párr. 296.

${ }^{78}$ La prueba más evidente de que la posición de la Corte en torno a las leyes de amnistía no ha sufrido modificaciones es que, el mismo año de la sentencia de la Gran Sala, el órgano interamericano volvió nuevamente a señalar que son inadmisibles las disposiciones de amnistía que pretendan impedir la investigación y sanción de los responsables de violaciones graves de los derechos humanos, despejando así cualquier posible duda acerca de cuál es su posición en torno a esta temática. Caso Tarazona Arrieta y otros vs. Perú, Excepción Preliminar, Fondo, Reparaciones y Costas, sentencia de 
explicaría en cierto modo por qué el Tribunal se va a limitar a tomar nota de los argumentos expuestos por los terceros intervinientes en su Informe, pero sin tomar en ningún momento partido por ellos, aunque sin descartarlos directamente.

Más allá de las posibles dudas que se hubiesen podido suscitar en el presente caso sobre la posición del Tribunal ante las leyes de amnistía, lo cierto es que, tras Margus v. Croacia, se confirma plenamente que la jurisprudencia europea se ha visto fuertemente influenciada por la interamericana, mostrando así que el diálogo judicial entre ambos sistemas de derechos humanos es una realidad. Tanto así que hoy en día es posible afirmar, sin ningún género de duda, que tanto el TEDH como la Corte comparten la misma idea de que las leyes de amnistía frente a graves violaciones de derechos humanos son incompatibles con las disposiciones de las Convenciones americana y europea de derechos humanos. Esta influencia recíproca que se da entre ambos tribunales regionales en distintos ámbitos constituye, en última instancia, una buena muestra del creciente proceso de cross-fertilization entre los dos sistemas de protección ${ }^{79}$.

\section{Conclusiones}

Existe en la actualidad una creciente tendencia al diálogo judicial entre el TEDH y la Corte IDH en distintos ámbitos temáticos relacionados con los derechos humanos. Hasta hace poco tiempo dicho diálogo se había caracterizado por ser un diálogo "unidireccional", en el sentido de que era el case law europeo el que irradiaba su influencia sobre el de su contraparte americana, sin que se diese el proceso inverso. Sin embargo, como hemos podido comprobar en el presente trabajo, se detecta un cambio en la naturaleza de dicho diálogo, al constatarse que la influencia entre ambos tribunales es ahora más bien recíproca, en una suerte de diálogo "bidireccional". Dicho cambio es perfectamente reconocible en el tema de las leyes de amnistía, ya que en decisiones relativamente recientes del TEDH, éste ha hecho mención

$\overline{15 \text { de octubre de } 2014}$, en Serie C, No. 286, párr. 155. Más recientemente, en su análisis sobre si la concesión por el Gobierno peruano de un "indulto por razones humanitarias" al ex presidente Alberto Fujimori, es compatible con el cumplimiento de la obligación de investigar, juzgar y sancionar a cargo del Estado peruano, la Corte americana dejó bien establecido que el estándar establecido en el Caso Barrios Altos, sobre la incompatibilidad del otorgamiento de amnistías cuando median graves violaciones de derechos humanos, "ha sido reiterado de forma constante en su jurisprudencia". Resolución de la Corte Interamericana de Derechos Humanos de 30 de mayo de 2018. Caso Barrios Altos y Caso La Cantuta v. Perú. Supervisión de cumplimiento de sentencia Obligación de investigar, juzgar y, de ser el caso, sancionar, párr.5.

79 Fabián Salvioli, "Convergencias y Divergencias de las jurisdicciones contenciosas en los sistemas europeo e interamericano de protección de los Derechos Humanos", [en Fabián Salvioli, y Claudio Zanghi, coords.: Jurisprudencia regional comparada de Derechos Humanos. El Tribunal Europeo y la Corte Interamericana, Valencia, Tirant lo Blanch, 2013], p. 82. 
específica los estándares establecidos en la jurisprudencia interamericana en esta temática y los ha asumido como propios. Las citas al case law interamericano le han servido al Tribunal no sólo como fuente inspiración o como ayuda en la interpretación de las disposiciones del $\mathrm{CEDH}$, sino que además - y este es lo más importante- han tenido una influencia decisiva en la resolución del caso; lo cual nos sitúa ante un claro supuesto de cross-fertilization. Como resultado de este proceso, hoy en día ambos tribunales comparten la misma idea de que las leyes de amnistía frente a graves violaciones de los derechos humanos son incompatibles con las disposiciones de las Convenciones europea y americana.

Este cambio de enfoque en el diálogo judicial entre estos tribunales supone un reconocimiento por parte del TEDH de que los órganos de protección del sistema interamericano y, más concretamente, la Corte IDH, constituyen socios particularmente importantes y respetados, y de que el case law interamericano goza de una reputada autoridad. Y de que, por tanto, el tribunal europeo puede aprender bastante de su contraparte americana. Por todo ello, estimamos que existe actualmente una base más que sólida para que ambos tribunales continúen dialogando y cooperando en la interpretación, especificación y garantía global de los derechos humanos. Ello, sin duda alguna, supondrá un importante aliciente para la armonización jurisprudencial entre tribunales de derechos humanos, favoreciendo así la unidad del sistema universal de protección. 


\section{Referencias bibliográficas:}

Rufina Amaya, Mark Danner, M. y Carlos Henríquez, Luciérnagas en El Mozote, San Salvador, Ediciones Museo de la Palabra y la Imagen, 2014, pp. 16-156.

Miguel Arenas Meza "La contribución de la jurisprudencia de la Corte Interamericana de Derechos Humanos a la eliminación de las "leyes de amnistía" [en América Latina: un paso decisivo en la lucha contra la impunidad", Actas del XIV Encuentro de Latinoamericanistas Españoles, Santiago de Compostela, Servicio de Publicacións de la Universidade de Santiago de Compostela, 2010],

Antonio Augusto Cançado Trindade, "Preface: International Tribunals and the Pursuance o Jurisprudential Harmonization in their Common Misssion of Realisation of Justice"[ en Carla Buckley, Alice Donald,. Philip Leach, eds.: Towards Convergence in International Human Rights Law. Approaches of Regional and International Systems, Leiden, Brill Nijhoff, 2017].

Jonas- Sébastien Beaudry, "La invalidez ab initio de las leyes de amnistía en América Latina: la contribución de la Corte Interamericana de Derechos Humanos", en Revista General de Legislación y Jurisprudencia, 1 (2010).

Eva Brems, "Transitional Justice in the Case Law of the European Court of Human Rights", en The International Journal of Transitional Justice, 2 (2011)

Laurence Burgorgue-Larsen, "La lutte contre l'impunité dans le systeme interaméricains des Drois de 1'Homme", en Cursos de Derechos Humanos de Donostia-San Sebastián, 10 (2009).

Chloe Cheeseman, "Harmonising the Jurisprudence of Regional and International Human Rights Bodies. A Literature Review" [en Carla Buckley, Alice Donald,. Philip Leach, eds.: Towards Convergence in International Human Rights Law. Approaches of Regional and International Systems, Leiden, Brill Nijhoff, 2017].

Javier Chinchón Álvarez, "Las leyes de amnistía en el sistema europeo de derechos humanos. De la decisión de la Comisión en Dujardin y otros contra Francia a la sentencia de la Gran Sala en Margus contra Croacia: ¿progresivo desarrollo o desarrollo circular?, en Revista de Derecho Comunitario Europeo, 52 (2015).

Angela Di Stasi, "La Corte interamericana e la Corte Europea dei diritti dell'uomo: da un transnational judicial dialogue ad una cross -fertilization?" [en Luisa Cassetti,, Angela Di Stasi y César Landa Arroyo, coords.: Diritti e giurisprudenza. La Corte interamericana dei diritti umani e la Corte europea di Strasburgo, Napoli , Jovene Editore, 2014]. 
Javier Dorado Porras, "Justicia transicional, persecución penal y amnistías" en Derechos y Libertades. Revista del Instituto Bartolomé de las Casas, 28 (2013).

José Esteve Moltó, "La jurisprudencia de la Corte Interamericana de Derechos Humanos ante las leyes de amnistía: un referente para la necesaria "fertilización" trasatlántica", en Eunomía, Revista en Cultura de la Legalidad, 9 (2016).

Magdalena Forowicz, The Reception of International Law in the European Court of Human Rights, Oxford, Oxford University Press, 2010.

_- "Factors influencing the reception of International Law in the ECtHR's case law: an overview", [en Mads Andenas, M. y Eirik Bjorge, eds., $A$ Farewell to Fragmentation. Reassertion and Convergence in International Law, Cambridge, Cambridge University Press, 2015]

Javier García Roca, "El Diálogo sobre Derechos Humanos entre el Tribunal Europeo y la Corte Interamericana" [ en Pablo Santolaya Marchetti e Isabel Wences, coords.: La América de los Derechos, Madrid, Centro de Estudios Constitucionales , 2016]

Lech Garlicki, "Universalism v. Regionalism? The Role of the Supranational Judicial Dialogue", [en Javier García Roca, Pablo Antonio Fernández Sánchez, Pablo Santolaya Machetti, y Raul Canosa Usera, eds.: El Diálogo entre los Sistemas Europeo y Americano de Derechos Humanos, Thomson Reuters, Pamplona, 2012]

Tania Groppi, y Ana María Lecis Cocco-Ortu, "Las referencias recíprocas entre el Tribunal Europeo y la Corte Interamericana de Derechos Humanos: ¿De la influencia al diálogo?, en Revista de Derecho Político (UNED), 91 (2014).

Louise Mallinder, Amnesty, Human Rights and Political Transitions. Bridging the Peace and Justice, Oxford, Hart Publishing, 2008.

, "The End of Amnesty or Regional Overreach? Interpreting the erosion of South America's Amnesty Laws, en International and Comparative Law Quarterly, (2016), disponible en: http://journals.cambridge.org/ abstract_S0020589316000166

Gerald Neuman, "Import, Export and Regional Consent in the Inter-American Court of Human Rights, en European Journal of International Law, 1 (2008). ," "The External Reception of Inter-American Human Rights Law, en Quebec Journal of International Law (Special Edition), (2011).

Oscar Parra-Vera, "Algunos aspectos procesales y sustantivos de los diálogos recientes entre la Corte Interamericana de Derechos Humanos y el Tribunal Europeo de Derechos Humanos" [en Pablo Santolaya Marchetti e Isabel Wences, coords., La América de los Derechos, Madrid, Centro de Estudios Constitucionales, 2016]. 
Flávia Piovesan, "Diálogo entre Cortes: A interamericanizaçao do sistema europeo e a europeizaçao do sistema interamericano"[en Flávia Piovesan y Jania María Lopes Saldanha, coords.: Diálogos Jurisdicionais e Direitos Humanos, Brasilia, Gazeta Jurídica Editora e Livraria Ltda. ME, 2016]

Fabián Salvioli, "Convergencias y Divergencias de las jurisdicciones contenciosas en los sistemas europeo e interamericano de protección de los Derechos Humanos", [en Fabián Salvioli, y Claudio Zanghi, coords.: Jurisprudencia regional comparada de Derechos Humanos. El Tribunal Europeo y la Corte Interamericana, Valencia, Tirant lo Blanch, 2013].

Dorothea Staes, "The importation of "External Sources" by the European Court of Human Rights. Opportunities and Challenges in Light of Legal Certainty", [en Mauricio Arcari, y Louis Balmond, eds.: Le dialogue des jurisdictions dans l'ordre juridique internationale. Entre pluralisme et securité juridique, Napoli, Ed. Scientifica, 2014]

Michail Vagias, "Revocation of Enduring Amnesties vs. Principles of Legality: Jurisprudential Contestations between the Inter- American Court of Human Rights and Domestic Courts", en Italian Yearbook of International Law, 26( 2016).

Erik Voeten, "Borrowing and Non-Borrowing among International Courts" en Journal of Legal Studies, 2 (2010).

Vera Vriezen, Amnesty Justified? The need for a case by case approach in the interests of human rights, Cambridge, Intersentia Ltd., 2012. 